\title{
What leads people to tolerate negative interest rates on their savings?
}

Citation for published version (APA):

Corneille, O., D'Hondt, C., De Winne, R., Efendic, E., \& Todorovic, A. (2021). What leads people to tolerate negative interest rates on their savings? Journal of Behavioral and Experimental Economics, 93, [101714]. https://doi.org/10.1016/j.socec.2021.101714

Document status and date:

Published: 01/08/2021

DOI:

10.1016/j.socec.2021.101714

Document Version:

Publisher's PDF, also known as Version of record

Document license:

Taverne

Please check the document version of this publication:

- A submitted manuscript is the version of the article upon submission and before peer-review. There can be important differences between the submitted version and the official published version of record.

People interested in the research are advised to contact the author for the final version of the publication, or visit the DOI to the publisher's website.

- The final author version and the galley proof are versions of the publication after peer review.

- The final published version features the final layout of the paper including the volume, issue and page numbers.

Link to publication

\footnotetext{
General rights rights.

- You may freely distribute the URL identifying the publication in the public portal. please follow below link for the End User Agreement:

www.umlib.nl/taverne-license

Take down policy

If you believe that this document breaches copyright please contact us at:

repository@maastrichtuniversity.nl

providing details and we will investigate your claim.
}

Copyright and moral rights for the publications made accessible in the public portal are retained by the authors and/or other copyright owners and it is a condition of accessing publications that users recognise and abide by the legal requirements associated with these

- Users may download and print one copy of any publication from the public portal for the purpose of private study or research.

- You may not further distribute the material or use it for any profit-making activity or commercial gain

If the publication is distributed under the terms of Article $25 \mathrm{fa}$ of the Dutch Copyright Act, indicated by the "Taverne" license above, 


\title{
What leads people to tolerate negative interest rates on their savings? ${ }^{\text {in }}$
}

\author{
O. Corneille ${ }^{\mathrm{a}}$, C. D’Hondt ${ }^{\mathrm{b}}$, R. De Winne ${ }^{\mathrm{b}}, \mathrm{E}$. Efendic ${ }^{\mathrm{c}}$, A. Todorovic ${ }^{*}$, b \\ ${ }^{\text {a }}$ Psychological Sciences Reserach Insitutute, UCLouvain, Louvain-la-Neuve, 1348, Belgium \\ b Louvain Finance (LIDAM), UCLouvain, Louvain-la-Neuve, 1348, Belgium \\ ${ }^{\mathrm{c}}$ Maastricht University, School of Business and Economics, Maastricht, 6211LM, Netherlands
}

\section{A R T I C L E I N F O}

\section{JEL classification:}

G11

G21

G40

G41

G51

G53

Keywords:

Negative interest rates

Savings accounts

\begin{abstract}
A B S T R A C T
Using an online experiment, we investigate intertemporal preferences to infer people's willingness to accept negative interest rates (NIRs) on their savings. We find some tolerance of NIRs, i.e., of people being willing to hold money in the bank rather than spend it, thereby accepting less savings at some future time. This tolerance strongly depends on the amount of savings, time horizon, actual savings behavior, and anchoring. Specifically, the higher the amount, the lower is the tolerance of NIRs, consistent with a reverse magnitude effect. Moreover, as the time horizon increases, the tolerance of NIRs decreases. Regular savers are more likely to tolerate NIRs than nonregular savers, which is consistent with status quo bias, higher familiarity with savings deposits, or a futureoriented mindset. We also find a higher tolerance of NIRs on savings when participants are anchored towards NIRs, i.e., when participants are first presented with NIRs and then with positive interest rates (PIRs).
\end{abstract}

\section{Introduction}

Interest rates refer to a percentage premium of money paid on a specified date for delaying consumption and risk-taking (Fisher, 1930). Any interest rate is composed of two parts: the risk-free rate and the risk premium. The higher the risk (i.e., uncertainty about outcomes), the higher is the risk premium. The risk-free rate captures the time value of money, which allows for comparison of different risk-free amounts of money at various points in time. Because interest rates were initially thought of as a premium, for a long time, it has been assumed that they could only be positive. However, since the 2008 financial crisis, several central banks in industrialized countries have brought their risk-free rates into negative territory (Altavilla, Burlon, Giannetti, \& Holton, 2019; Brown, 2018). NIRs represent a historical precedent as well as a paradigm shift. Instead of rewarding delayed consumption, NIRs punish it. In practice, NIRs imply that banks will require depositors to pay to hold money on savings accounts (which some banks have already started to do). ${ }^{1}$
NIRs are essentially viewed as a monetary policy tool aimed at boosting economic growth by stimulating risk-taking and/or spending (Agarwal \& Kimball, 2015; Kimball, 2015). The rationale behind their implementation is that people are not likely to tolerate NIRs because they are associated with certain losses. Because individuals are indeed punished for saving money when NIRs are applied, they should instead prefer to spend it, invest it, or lend it. Hence, people are not expected to tolerate NIRs on their savings (Block, 1978; Lilley and Rogoff, 2020). The reality, however, is more puzzling. On the one hand, there is some empirical evidence that NIRs may effectively promote risk-taking and spending, but mainly among institutional investors (Maggio \& Kacperczyk, 2017; Hong \& Kandrac, 2018). On the other hand, in several countries that are experiencing all-time low or negative rates, aggregate household savings seems rather demonstrate the opposite since savings are still increasing (Europe, 2019).

Because the existence of NIRs on regular savings accounts flips standard practices on their head, it is of utmost importance to better understand to what extent people will accept a situation in which they

\footnotetext{
is The authors gratefully acknowledge financial support from the Belgian French-speaking community (ARC grant 18/23-089). They thank the editor and three anonymous referees for insightful comments which helped improve the paper.

* Corresponding author.

E-mail addresses: olivier.corneille@uclouvain.be (O. Corneille), catherine.dhondt@uclouvain.be (C. D’Hondt), rudy.dewinne@uclouvain.be (R. De Winne), efenemir@gmail.com (E. Efendic), aleksandar.todorovic@uclouvain.be (A. Todorovic).

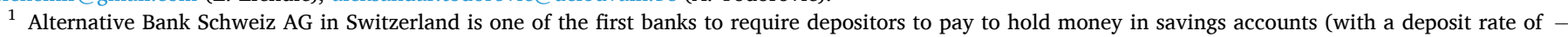

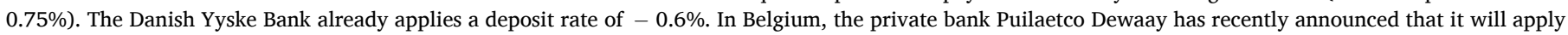
NIRs for wealthy depositors, while the Dutch online broker DeGiro plans to apply NIRs on deposits exceeding $\$ 2,500$.
} 
have to pay banks some interest (in addition to traditional bank fees) ${ }^{2}$ to hold money on their savings accounts. A growing body of research investigates the decision-making process of individuals in the face of low or negative interest rates. Most authors focus on investment decisions and risk-taking, and their results relate low or negative rates to a higher appetite for risk (Bracha, 2020; Ganzach \& Wohl, 2018; Lian, Ma, \& Wang, 2018; Baars, Cordes, \& Mohrschladt et al., 2020; David-Pur, Galil, \& Rosenboim, 2020). ${ }^{3}$ Our research question differs in this paper since we focus on savings (instead of investing) and aim at determining what leads people to tolerate NIRs on their savings. For that purpose, we build on Efendic, D'Hondt, De Winne, Corneille (2019), who are the first, to the best of our knowledge, to provide preliminary insights into the factors that may modulate people's tolerance for NIRs on savings. Using two experiments, these authors rely on direct questions to assess participants' tolerance towards penalties or NIR that apply to savings deposits. ${ }^{4}$ Their results indicate that individuals show a surprisingly large tolerance for NIRs when the only alternative is to take one's savings out of the bank. Moreover, Efendic et al. (2019) find that this tolerance fluctuates as a function of the size of savings, the size of the NIR, and some individual characteristics such as age, gender and risk-taking inclinations.

In this paper, we determine people's intertemporal preferences to infer their willingness to accept NIRs on their savings. Compared to Efendic et al. (2019) who use direct questions, our approach is indirect, but particularly well-suited to include different time horizons. Specifically, we use an online experiment on Prolific to evaluate intertemporal preferences based on a set of binary choices between spending money today or saving it for the future. ${ }^{5}$ Crucially, what is innovative in our

\footnotetext{
${ }^{2}$ Interest rates differ from bank fees. For regular savings accounts, bank fees refer to nominal fees for account setup and maintenance as well as transactional services. Such fees can be one-time, recurrent, or related to specific operations. Interest rates relative to regular savings accounts are risk-free rates; i.e., they do not include any risk premium (since there is no risk-taking by the saver). Such interest rates aim at capturing the time value of money, which allows for comparisons of different risk-free amounts of money at various points in time.

3 Bracha (2020) reports no difference in investment decisions made by individuals faced with positive and negative interest rates. While not directly dealing with NIRs, Ganzach and Wohl (2018) provides evidence that the lower the risk-free rate, the higher is the demand for risky assets. Baars, Cordes, and Mohrschladt et al. (2020) find significantly increased risk-taking only when interest rates turn negative. Lian et al. (2018) find that lower interest rates are associated with higher allocations to stocks and lower allocations to cash. David-Pur et al. (2020) conduct a series of lab experiments to analyze both borrowing and investment behavior in the PIR and NIR context. They find that the zero-interest rate has the strongest impact on individuals' investment decisions.

4 Specifically, Efendic et al. (2019) ask all participants to imagine that all banks have introduced a new policy where one is required to pay to keep savings in the bank. In the first experiment, participants are asked questions in the following format: You saved $\mathrm{X}$ on your account. To have access to it on your bank account for the next 1 year, would you be willing to pay $\mathrm{X} \%$ of that amount?". In the second experiment, the questions are adjusted to explicitly mention that the payment will occur at the end of the year. For more details, see Efendic et al. (2019).

${ }^{5}$ In the literature, two methods are used to measure intertemporal preferences: the matching-based method and the choice-based method. In the former, participants are provided with a given amount of money at a specific point in time (e.g., \$20 today) and are asked to express the monetary equivalent at another point in time that makes them indifferent (e.g., \$X in one year). This approach is cognitively demanding and can lead to extreme answers (Urminsky \& Zauberman, 2015). The choice-based method relies on a set of binary choices that are presented to participants (e.g., \$20 today or \$25 in one year; \$20 today or $\$ 30$ in one year, etc.). Since participants have to select just one option to express their preferences, this approach is easy to understand. However, how the sequence of choices is presented can potentially bias the decisions. Therefore, one needs to control for the sequence of choices when applying this choice-based method.
}

setting is that we present participants with future values of savings that may be higher than, equal to or lower than the present value of savings at their disposal. As explained before, lower future values of savings would imply that NIRs have been applied to a deposit. Based on participants' intertemporal preferences over two amounts $(\$ 500$ and $\$ 20,000)$ and five time horizons (from 6 months to 10 years), we first estimate the indifference points, i.e., future amounts of savings that participants require to continue to save money. Subsequently, using the indifference points and the corresponding present values of savings, we are able to infer annual implicit discount rates, which allows for meaningful comparisons across amounts and horizons. In our setting, the discount rate refers to the annualized interest rate at which the decision-maker is willing to continue to save money (instead of spending it immediately on goods or services).

To control for the sequence of binary choices, we define two anchoring conditions in our setting. In the Ascending condition (from NIRs to PIRs), the sequence of choices provides increasing future amounts of savings, which are preset to annual interest rates of $-4 \%$, $2 \%, 0 \%, 2 \%$, and $4 \%$. By contrast, in the Descending condition (from PIRs to NIRs), the sequence of future amounts is reversed, i.e., future amounts are preset to an annual interest rate of $4 \%, 2 \%, 0 \%,-2 \%$, and $-4 \%$. Because preferences can be affected by previous choices, we hypothesize that the decisions made in the Ascending condition should lead to a higher acceptance of NIRs than those made in the Descending condition.

This piece of experimental research is innovative in several ways. First, we determine annual implicit interest rates on savings for different amounts and time horizons, allowing people to express negative discounting. As mentioned above, our approach is more indirect that the one applied in Efendic et al. (2019). Its key advantage is to allow for meaningful comparisons across both amounts and time horizons. Although Efendic et al. (2019) only use one single time horizon (one year) in their two experiments, they point out that how people's time preferences would relate to NIRs is another important aspect to probe into. In this paper, we fill the gap and provide insights into how the tolerance to NIRs is related to the time horizon. Second, our two anchoring conditions allow us to compare decisions made by individuals depending on whether they face NIRs or PIRs first. By contrast, Efendic et al. (2019) focus exclusively on NIRs and do not consider PIRs (which is consistent with their approach). Third, we should stress that the range of interest rates in our experiment varies from $-4 \%$ to $4 \%$, while previous research only considers slightly negative rates. The lowest risk-free rate is equal to $-1 \%$ in Lian et al. (2018) and Baars, Cordes, and Mohrschladt et al. (2020), $-2 \%$ in David-Pur et al. (2020), or $-3 \%$ in Bracha (2020). In Efendic et al. (2019) who focus on savings as we do, only three values are considered for NIRs, namely, $-0.3 \%,-0.6 \%$, and $-1 \%$. Fourth, we relate discount rates to decision-makers' actual savings behavior and financial literacy, which is really innovative in the scarce literature devoted to NIRs. ${ }^{6}$ Past research reports that financially literate individuals are more likely to save money (Lusardi, 2008) and can better observe the benefits of saving and investing (Anantanasuwong, 2019). We posit that since financially literate people have a higher propensity to plan for retirement (Lusardi \& Mitchell, 2007; Van Rooij, Lusardi, \& Alessie, 2012), they are more likely to tolerate NIRs on their savings than their counterparts. In addition, a higher familiarity with the low level of interest rates paid on savings deposits over the last decade and/or a more future-oriented mindset should make them more tolerant to NIRs than individuals with low financial literacy.

The main results of the paper can be summarized as follows.

\footnotetext{
${ }^{6}$ Efendic et al. (2019) do not include actual savings behavior and financial literacy in their study. They focus on the following individual differences: age, gender, education, income, risk-propensity, numeracy, and ability to delay gratification. They obtain significant differences in NIR tolerance with regards to age, gender, and risk-propensity. For more details, see Efendic et al. (2019).
} 
Participants show intertemporal preferences revealing that they are willing to accept lower future values (i.e., accept NIRs) on savings, and these preferences depend on several factors. First, participants are more likely to tolerate NIRs for the low amount of savings ( $\$ 500)$ than for the high amount $(\$ 20,000)$. This result is consistent with a reverse magnitude effect. One possible reason for this effect is that the interest to be paid appears lower in absolute terms for the small amount of savings than for the corresponding interest on the large amount of savings. Second, annual implicit interest rates are positively associated with the time horizon - the longer the horizon, the lower is the tolerance of NIRs. This result is consistent with people's reluctance to accept recurrent losses or to commit to losses for longer time horizons. Third, participants who save money regularly are more likely to tolerate NIRs than those who are not regular savers. We relate this finding to the status quo bias, a higher familiarity with savings deposits, and/or a future-oriented mindset (i.e., regular savers have put savings aside for the future and NIRs cannot compromise that future). Next, participants who face future values implying NIRs first (in the Ascending condition) are more likely to tolerate NIRs than participants who face future values implying PIRs first (in the Descending condition). This result is consistent with anchoring and/or satisficing behavior. We however find no significant difference related to financial literacy. Since the level of financial literacy is pretty high among our participants, we cannot exclude that this finding is (at least partially) due to a lack of heterogeneity in the sample.

The remainder of the paper is organized as follows. Section 2 reviews the relevant literature and presents our hypotheses. Section 3 describes our experimental setting. Section 4 reports the results. Section 5 concludes.

\section{Literature and hypotheses}

\subsection{Why do people discount future monetary outcomes?}

Why people tend to discount future monetary outcomes has been extensively addressed in the decision-making literature. Given our research question, we focus on the main economic reasons. The first driver is the opportunity cost, which represents the benefits of the second-best alternative. Let us take a simple example wherein a decision-maker is offered $\$ 100$ today or $\$ 110$ in one year. His/her choice depends on the opportunity cost. If he/she can put the available money in a bank account and receive $\$ 120$ in return after one year, the gain from this alternative is higher than the gain from choosing the future amount $(\$ 120>\$ 110)$. The difference between these two alternatives is $\$ 10$ ( $\$ 120$ - $\$ 110$ ), and the best choice for him/her is to take the money now and deposit it in the bank for one year. If the bank offers only $\$ 105$ after one year, he/she is more likely to take the future amount ( $\$ 110)$ because it delivers a higher gain $(\$ 110-\$ 105=\$ 5) .^{7}$ The opportunity cost is then an important determinant of discounting that matters for both gains and losses. The higher the benefits of the alternative, the higher is the discount rate.

The second reason for discounting future monetary outcomes is uncertainty. The present is always certain, whereas the future is consistently related to some uncertainty. The uncertainty of human life can decrease the value of future monetary outcomes (i.e., "A bird in the hand is worth two in the bush"). People may worry that an accident might happen before they can receive their future reward. This could make immediate monetary options more favorable than future ones.

\footnotetext{
7 In the cases of losses, the decision-maker is offered the choice to pay a debt of $\$ 100$ today or $\$ 110$ in one year. If the bank offers $\$ 120$ in a year, a better option for him/her is to postpone the payment and deposit the money in the bank. If he/she does that, he/she can take $\$ 120$ from the bank after one year, pay the debt (\$110), and keep \$10 as gain. If the bank offers only \$105 in one year, it is better to pay the debt immediately because the money available in one year is not enough to pay the debt entirely $(\$ 105<\$ 110)$.
}

Morbidity and mortality are additional reasons for worries regarding future payments. For instance, lower discount rates are observed among college students and teenagers than among soldiers who live in a risky and violent atmosphere wherein the risk of mortality is higher (Lahav, Benzion, \& Shavit, 2011). Individuals with bad health conditions also have higher discount rates than their healthier counterparts (Chao et al., 2009).

In the same vein, expectations about available resources in the future $^{8}$ are another driver of discounting. When expecting to receive additional money in the future and facing options related to gains, decision-makers are more likely to choose the immediate option ("I will have more money in the future, and I can spend the money now"). In contrast, decision-makers can postpone payments (losses) if they expect that their financial capacity will be better in the future ("I will have more money in the future, and I can pay that bill later even though it will cost me more").

\subsection{Why do we observe differences in discount rates?}

In the literature devoted to intertemporal preferences, several factors affecting discount rates for monetary outcomes have been proposed. First, discount rates for gains and losses differ significantly, meaning that the sign of the possible outcome plays a role. Because failing to wait for a reward creates an opportunity cost whereas postponing a loss creates an additional cost (Thaler, 1980), discount rates for losses are expected to be smaller than those for gains. Thaler (1981) finds that gains are typically related to higher discount rates than losses. Hardisty, Appelt, and Weber (2013a) also find lower discount rates for losses than for gains; for small losses, discount rates are slightly negative, while for large losses, discount rates are slightly positive.

The amount of money at stake is the second reason for the differences in discount rates. This is the so-called magnitude effect. Thaler (1981) finds a negative relationship between the size of gains and discount rates. For larger gains, discount rates are lower than those for smaller gains. For example, people prefer $\$ 5$ today over $\$ 6$ in a year but are willing to wait one year to get $\$ 6,000$ over $\$ 5,000$ today. Read et al. (2013) explain that this magnitude effect occurs because decision-makers pay attention to the absolute difference between the amount available today and its future value. In the above example, the case of $\$ 5$ implies a difference of only $\$ 1(\$ 6-\$ 5)$, while the difference is much higher in the second case $(\$ 1,000(\$ 6,000-\$ 5,000))$. The gain of $\$ 1,000$ appears much more attractive than the gain of $\$ 1$, although the discount rate is the same (20\%) in both cases. Breuer, Soypak, and Steininger (2020) explore the differences in discount rates for gains and losses by drawing a distinction between an interest-rate frame and a money frame. ${ }^{9}$ For gains, these authors find a negative relationship between the outcome size and discount rates regardless of the prevailing frame, consistent with a conventional magnitude effect. However, they document a reverse magnitude effect for losses in the interest-rate frame. This means that as the amount of money at stake increases, the interest rate also increases (i.e., interest rates are higher for larger losses than for smaller losses). Accordingly, people would prefer to receive $\$ 4.2$ after one year instead of $\$ 5$ today more than they would prefer to receive $\$ 4$, 200 after one year instead of $\$ 5,000$ today. In this example, the loss of $\$ 800$ seems much higher than the loss of $\$ 0.8$, although the discount rate is the same in both cases $(-20 \%)$. Efendic et al. (2019) find that the

\footnotetext{
${ }^{8}$ In the psychological literature, the concept of resource slack refers to the future availability of a certain resource (such as time or money). Zauberman and Lynch (2005) find that time is discounted more steeply than money.

9 In a money frame, participants have to choose between two monetary outcomes, and the corresponding implicit interest rate between the present amount and its future value is not revealed. By contrast, in an interest-rate frame, the implicit interest rates of return from alternative outcomes (instead of the monetary values) are directly presented to participants.
} 
tolerance for NIRs is higher for small than for large amounts, which supports this reverse magnitude effect.

Mental accounting, whereby decision-makers have different mental accounts for small and large amounts, could also explain the magnitude effect. Small amounts are more easily associated with current expenditures (e.g., buying clothes, going on vacation, etc.), whereas large amounts are more easily seen as savings or outstanding spending (e.g., buying a car, a house, etc.). However, mental accounting does not help explain the discount rates for small and large losses (Hardisty et al., 2013a).

Another driver of differences in discount rates is hyperbolic discounting, i.e., decision-makers typically have a declining discount rate as the time horizon increases (Ainslie \& Haslam, 1992). The longer the horizon, the lower is the discount rate. Thaler (1981) reports that when people are asked how much money they would require in one month/one year/ten years to make them indifferent towards the option of receiving $\$ 15$ now, their responses are $\$ 20, \$ 50$ and $\$ 100$, respectively, which implies an annual interest rate ${ }^{10}$ of $345 \%$ for the one-month horizon, $120 \%$ for the one-year horizon and $19 \%$ for the ten-year horizon. Such differences in discount rates are potentially due to the compounding effect, which is hard to consider because of the accumulation of interest on interest. Decision-makers who do not consider the compounding effect might think that it is enough to multiply the initial rate per period by the number of periods. Therefore, as the number of periods increases, their future values also increase but at a decreasing rate. ${ }^{11}$ Since the compounding effect is more prominent as the time horizon increases, this phenomenon is more likely to appear for longer than for shorter horizons. However, in the case of losses, neither a positive nor a negative correlation between the time horizon and discount rates has been observed.

Discount rates also depend on financial literacy. Lusardi and Mitchell, 2011 defines financial literacy as basic knowledge regarding compounding, inflation, and diversification. These authors show that low financial literacy may lead decision-makers to make mistakes that are very often irreversible. Furthermore, financially literate people are more likely to save money (Lusardi, 2008) and to plan for retirement (Lusardi \& Mitchell, 2007; Van Rooij et al., 2012; Anantanasuwong, 2019). Focusing on the impact of financial literacy on time preferences, Lahav, Rosenboim, Shavit et al. (2015) find that higher financial literacy decreases subjective discount rates. These authors define the subjective discount rate as the rate at which individuals trade current and future values, which is assumed to be higher for individuals who are more focused on the present and lower for those who are more future-oriented.

The order of immediate outcomes in the experimental setting also drives some differences in discount rates. When presented to decisionmakers, immediate outcomes can be ascending, descending or random. Immediate outcomes in ascending order are displayed from lowest to highest. For example, decision-makers are first presented with $\$ 100$ today against $\$ 110$ in one year and then with $\$ 1,000$ today against $\$ 1,100$ in one year, etc. The descending order is just the opposite-immediate outcomes are presented from the highest to the lowest (i.e., we first show $\$ 1,000$ today as opposed to $\$ 1,100$ in one year and subsequently $\$ 100$ today against $\$ 110$ in one year). The random order includes some randomization in the selection of immediate outcomes. The order of immediate outcomes is not trivial. Robles and Vargas, 2007

\footnotetext{
10 Using a continuous compounding formula.

11 Let us consider an example for gains. Decision-makers are faced with the choice of receiving $\$ 1,000$ today or $\$ 1,100$ in a year. After that first decision, they are faced with the choice of receiving $\$ 1,000$ today and $\$ 1,610.51$ in 5 years. The interest for one year is $\$ 100$ and for 5 years is $\$ 610.51$. In both cases, the annual interest rate is $10 \%$. Decision-makers unfamiliar with compounding might think that the second option (with 5 years) yields a higher interest rate and may be more likely to accept the second option than the first one.
}

determine the highest discount rates in descending order, slightly lower discount rates in ascending order, and the lowest discount rates in random order. They explain these results through the influence of past responses on future ones.

\subsection{Why might people accept NIRs on their savings?}

Although NIRs are often viewed as a monetary policy tool aimed at boosting risk-taking and/or spending (Lilley and Rogoff, 2020), aggregate household savings are still increasing in countries experiencing all-time low rates ${ }^{12}$ or NIRs (Europe, 2019). Such an observation is puzzling and raises the critical question: why might people accept NIRs on their savings?

At the root of the implementation of NIRs is the belief that NIRs can boost economic growth, as individuals (just as financial institutions and firms) are penalized for hoarding money when they could spend it, lend it, or invest it instead. Because individuals tend to be loss averse (i.e., weight losses higher than gains $)^{13}$ and may regard NIRs as a certain loss, they should not tolerate them. Nevertheless, in reality, the observed facts may turn out to be different. There are at least three reasons why people might show some tolerance for NIRs.

The first reason is the precautionary motive, which explains why people save money. They save money to match future needs, i.e., expected and/or unplanned expenditures. By doing so, people aim to ensure the security of future payments. This precautionary motive is especially related to uncertainty regarding future incomes. When uncertainty is high, people will start to save or will save more to mitigate this uncertainty (Aizenman, Cavallo, \& Noy, 2015). This is known as precautionary savings, i.e., extra savings (Lugilde, Bande, \& Riveiro, 2019). As uncertainty increases, current savings also increase (Merrigan \& Normandin, 1996). Over the last decade, uncertainty has increased in many countries because of economic, political, and/or financial disturbances. In particular, most people are aware that monetary policy rates set by central banks and risk-free rates in general have reached all-time low (or even negative) levels in the aftermath of the 2008 financial crisis. Beyond the descending pattern of risk-free rates, the implementation of NIRs itself has acted as a red flag, i.e., a warning signal about the highly uncertain economic situation in most of the industrialized countries. Hence, this increasing uncertainty could explain why aggregate household savings are still increasing, despite all-time low rates or NIRs.

The next reasons relate to how people prefer to save money. Safekeeping is one of the oldest functions of banking (Lord, 1985). In this respect, banks obviously add value since saving money in a bank is safer than holding cash at home, where the risk of robbery is higher $(\mathrm{He}$, Huang, \& Wright, 2008). In addition, the practicality associated with bank accounts is attractive. Deposit accounts are often considered advantageous (or even necessary) for easy management of one's money (e. g., for online payments, access, transfer, etc.). ${ }^{14}$ Such practicality is important in an increasingly cashless society. We could add that in many industrialized countries, money kept in bank deposits is insured by the government (up to certain amounts). Such insurance might work in favor of saving money in banks.

Finally, we should stress that people's trust in the banking system could also play a role. Using household survey data from Central, Eastern and Southeastern European countries, Stix (2013) documents that a lack of trust in banks and memories of past banking crises are important determinants of why individuals prefer to hold assets in cash

\footnotetext{
${ }^{12}$ Even when nominal rates are still positive, real rates may be negative because of the inflation rate.

${ }^{13}$ This finding is a cornerstone of prospect theory (Kahneman \& Tversky, 1979) and is widely documented in the decision-making literature.

${ }^{14}$ Bank safe-deposit boxes fulfill the safekeeping function but do not offer the same practicality as bank deposits.
} 
rather than in banks. In addition, he reports that cash preferences are negatively related with wealth and financial literacy but positively related to risk aversion.

\subsection{Hypotheses}

Building on the literature, we formulate five hypotheses to be tested in our experiment.

The first hypothesis is related to the aforementioned magnitude effect. Since NIRs are associated with losses, we expect a reverse magnitude effect, ${ }^{15}$ i.e., participants are expected to require higher annual interest rates for the high amount of savings $(\$ 20,000)$ than for the low amount (\$500). Accordingly, participants should be more likely to tolerate NIRs for lower levels of savings. However, in our setting, each participant makes a set of choices involving either a positive or a negative interest rate, regardless of the anchoring condition. In the Descending condition, participants first face future values implying PIRs (so that they start in the domain of gains). Therefore, we expect a lower reverse magnitude effect for the participants in the Descending condition.

The second hypothesis captures the impact of time on annual implicit interest rates. Based on hyperbolic discounting, annual implicit rates of interest are expected to decrease as the time horizon increases. Thaler (1981) finds this negative relationship for gains, but no clear evidence is reported for losses. For the latter, a misunderstanding of the compounding effect could have the opposite impact to that related to gains. Let us use a simple example to illustrate this effect. Imagine decision-makers have to choose between taking $\$ 1,000$ today or holding that amount in savings to receive $\$ 900$ in one year. After that first decision, they have to choose between taking $\$ 1,000$ today or holding it in savings to receive $\$ 590.49$ in 5 years. The interest is negative and amount to $-\$ 100$ for one year and $-\$ 409.51$ for 5 years. Although both future amounts are based on an annual interest rate of $-10 \%$, losing $\$ 409.51$ in interest after 5 years might seem more acceptable than losing $\$ 100$ in a single year. On the other hand, for NIRs, another aspect could come into play: people might simply be reluctant to accept recurrent losses. Put differently, it might be harder to commit to losses for a longer time horizon. Consequently, we hypothesize that annual implicit interest rates will be higher for longer time horizons. Participants should then be more likely to tolerate NIRs when saving for shorter horizons. Again, the strength of this relationship could differ depending on the anchoring condition. In the Descending condition, participants first face future amounts implying PIRs, which means they start in the domain of gains. By contrast, in the Ascending condition, participants first face future amounts implying NIRs, which put them directly in a frame of losses. Participants could face NIRs in both conditions, but the anchoring difference could generate a positive but weaker relationship between annual interest rates and the time horizon in the Descending condition.

The third hypothesis considers individual savings behavior. We hypothesize that participants who save money regularly are more likely to tolerate NIRs on savings than those who are not regular savers. This hypothesis builds on status quo bias, which refers to people's preference to keep things the same by doing nothing (Samuelson \& Zeckhauser, 1988). The potential causes of this psychological phenomenon are regret avoidance and drive for consistency. Regret avoidance means that decision-makers feel worse when bad consequences result from action rather than inaction. In our setting, status quo bias could lead participants to continue to save money (inaction) rather than remove their money from the bank (action). The drive for consistency is the belief that past decisions are optimal. In our setting, this could make

\footnotetext{
15 Since our participants are not directly informed of interest rates, we are in a monetary frame. However, since they are requested to make decisions related to their savings, the context itself leads them to adopt a return-oriented view (instead of a money-oriented view). For more details on this aspect, please refer to Breuer et al. (2020).
}

decision-makers disregard new information to maintain their original decisions (i.e., continue to save money in the bank regardless of the updated conditions). Alternatives to the status quo bias might also explain why a higher tolerance for NIRs is expected among participants who are regular savers in reality. On the one hand, their familiarity with savings might make them aware of the (all-time) low interest rates offered by commercial banks over the last decade. We may assume that individuals who are not used to save regularly are not so familiar with the interest rates paid on savings deposits. On the other hand, regular savers might have a specific mindset, i.e., they are more future-oriented than the ones who do not save money on a regular basis. According to Efendic et al. (2019), people might tolerate NIRs to be consistent with their savings commitment, i.e., they put savings aside for the future and NIRs cannot compromise that future (Ariely \& Norton, 2008; Cialdini, 2009). Furthermore, the implementation of NIRs might act as a red flag about high uncertainty in the economic system, which might push people towards safer assets and make them tolerate small losses to ensure their future.

The fourth hypothesis is linked to financial literacy, i.e., general knowledge regarding compounding, inflation and diversification (Lusardi and Mitchell, 2011). More financially literate participants are expected to be more tolerant of NIRs on savings than less financially literate participants. This hypothesis is consistent with a higher propensity to plan for retirement among financially literate people (Lusardi \& Mitchell, 2007; Van Rooij et al., 2012). A low level of financial literacy may stimulate immediate consumption instead of savings (regardless of the offered conditions). In addition, financially literate individuals are more likely to save and then to be more familiar with the low level of interest rates paid on savings deposits. They are also more future-oriented, as suggested in Lahav et al. (2015). Both higher familiarity and more future-oriented mindset are expected to increase the tolerance to NIRs.

The fifth hypothesis aims to control for the sequence of choices. Consistent with anchoring bias ${ }^{16}$, we assume that the annual implicit interest rates in the Ascending condition are lower than those in the Descending condition. In the Ascending condition, anchors are the lowest future values that imply NIRs, which should make participants more tolerant of NIRs. In the Descending condition, anchors imply PIRs, which should make participants less tolerant of NIRs. Such expectations might also be related to satisficing behavior (Itzkowitz, Itzkowitz, \& Rothbort, 2015). Individuals are said to be satisficers because when facing a large number of options, they tend to choose the first acceptable option rather than the best possible one. In our setting, the first acceptable option in the Ascending condition is more likely to be an annual implicit rate that is lower than the one corresponding to the first acceptable option in the Descending condition.

\section{Experimental setting}

The experiment is conducted using oTree (Chen, Schonger, \& Wickens, 2016). All participants are directed to imagine that the central bank of their country applies an active interest rate policy, which aims at stimulating economic growth and consumption. They are also asked to imagine that there is only one commercial bank in their country and that they have accumulated some savings in their account at that bank. Participants are informed that interest rates on savings can be either positive or negative. They are then asked to decide whether they prefer to remove their money from the bank to spend it immediately on goods and/or services or continue to save for a given horizon. There is no risk, regardless of whether they remove the money from the bank to spend it

\footnotetext{
16 Anchoring is a particular type of priming effect whereby initial exposure to a number serves as a reference point and influences subsequent judgments about value. The process usually occurs without our awareness (Tversky \& Kahneman, 1974).
} 
For the purpose of this study, we are going to ask you to imagine that the Central Bank of your country applies an active interest rate policy, which aims at stimulating economic growth and consumption. Imagine also that there is only one commercial bank in your country.

Interest rates on savings can be either positive or negative. If interest rates on savings are positive, savers will have more money on their savings account in the future than now. If interest rates on savings are negative, savers will have less money on their savings account in the future than now.

Click on the Next button to continue reading instructions.

Imagine that there is only one commercial bank and that you have accumulated some savings on your bank account in that bank. You are going to decide whether you prefer to take money now from the savings account to spend it immediately on goods and/or services or keep saving that amount of money for the future. The safety of your deposit is guaranteed by the Central Bank, which ensures your money and guards against bank failure. If you take the money now from the savings account to spend it immediately on goods and/or services, there is no risk of losing it (i.e. robbery, loss, etc.), since you consume that amount of money immediately on goods and/or services. For different amounts of savings, you will be presented several corresponding future values and various time horizons. For each amount of savings and each time horizon, you need to make your decision.

Click on the Next button to continue reading instructions.

The experiment consists of two parts - the decision making part and the questionnaire. You will be presented in total $\mathbf{1 0}$ pages in the decision making part and $\mathbf{1}$ page in the questionnaire.

On each page in the decision making part, you will be asked to choose between options in this form:

Please choose between these two options:

O Take now savings of $\$ 500$ to spend it immediately on goods and/or services

O Keep on saving $\$ 500$ today in the bank to get $\$ 495$ in 3 months

There are no correct or incorrect answers. We just want to measure your preferences.

Click on the Next button to start playing.

Next

Fig. 1. Computer screenshot of instructions.

or save it in the bank for the future. The full instructions are presented in Fig. $1 .^{17}$

The experiment includes 10 web pages that present various savings amounts and different time horizons. The savings amount is either high $(\$ 20,000)$ or low $(\$ 500)$. The time horizon ranges from 6 months to 1,2 , 5 or 10 years. Each participant moves through the 10 pages with different amounts and horizons, but the order of the savings amounts ( $\$ 20,000$ versus $\$ 500$ ) and horizons is randomized to avoid the order effect for immediate outcomes (Robles and Vargas, 2007).

Our experiment has a mixed design with one factor that is betweensubject, the anchoring condition (Ascending vs. Descending), and two factors that are within-subject, the time horizon and amount of savings. In both anchoring conditions, each page includes from one to five binary

\footnotetext{
17 These instructions contain an example of binary choice, which is based on the low amount of savings ( $\$ 500$ ) and a future value of $\$ 495$ in 3 months. This might create some anchoring and lead to a greater acceptance of NIRs for the low amount of savings. If any, such an anchor should however be very weak since (1) the amount of savings is randomized, and (2) participants are presented first with binary choices implying PIRs in the Descending condition or NIRs in the Ascending condition.
}

choices. For each choice, the first option is to remove the money from the bank to spend it immediately on goods and/or services, while the second option is to hold it in savings for the future. For each page, the present amount of savings is constant (either $\$ 500$ or $\$ 20,000$ ). The sequence of future amounts depends on the anchoring condition. In the Ascending condition, the sequence increases from the first to the fifth binary choice, with future amounts preset to annual interest rates of $4 \%,-2 \%, 0 \%, 2 \%$, and $4 \%$. Once the participant decides to continue to save money for the future, he/she moves to another page. For example, if in the first binary choice the participant opts for the future amount that yields $-4 \%$, he/she moves to the next page. By contrast, if his/her first choice is to take the money and spend it immediately (instead of saving it for the future to receive $-4 \%$ ), he/she faces the second binary choice with a future value that yields $-2 \%$. Again, if the participant takes the future amount (with $-2 \%$ ), he/she moves to the next page. The decision-making process for the Ascending condition is presented in Fig. 2. In the Descending condition, the sequence of future outcomes is reversed-future amounts are preset to annual interest rates of $4 \%, 2 \%$, $0 \%,-2 \%$ and $-4 \%$. Figure 3 displays the decision-making process in the Descending condition.

Our experiment includes a questionnaire presented after the 


\author{
Please choose between these two options: \\ - Take now savings of $\$ 20000$ to spend it immediately on goods and/or services \\ Keep on saving $\$ 20000$ today in the bank to get $\$ 19216$ in 1 year
}

\begin{abstract}
Please choose between these two options:
- Take now savings of $\$ 20000$ to spend it immediately on goods and/or services

Keep on saving $\$ 20000$ today in the bank to get $\$ 19604$ in 1 year

Please choose between these two options:

Take now savings of $\$ 20000$ to spend it immediately on goods and/or services

- Keep on saving $\$ 20000$ today in the bank to get $\$ 20000$ in 1 year
\end{abstract}

\section{Next}

Fig. 2. Computer screen—decision-making in the Ascending condition.

\begin{abstract}
Please choose between these two options:
Take now savings of $\$ 20000$ to spend it immediately on goods and/or services

- Keep on saving $\$ 20000$ today in the bank to get $\$ 20816$ in 1 year
\end{abstract}

\begin{abstract}
Please choose between these two options:
Take now savings of $\$ 20000$ to spend it immediately on goods and/or services

- Keep on saving \$20000 today in the bank to get \$20404 in 1 year
\end{abstract}

Please choose between these two options:

- Take now savings of $\$ 20000$ to spend it immediately on goods and/or services

Keep on saving $\$ 20000$ today in the bank to get $\$ 20000$ in 1 year

Fig. 3. Computer screenshot-decision-making in the Descending condition.

decision-making section and including several items that relate to financial literacy, savings behavior, and the purpose of savings. The financial literacy item consists of three questions addressing compounding, inflation, and diversification (Meier \& Sprenger, 2013). The question about savings behavior is dichotomous: does the participant save money regularly or not? The last question is related to the purpose of savings. Our goal is to investigate the relationship between these items and annual implicit interest rates. The specific questions are available in Appendix A.

All participants in the experiment are paid a fixed reward of $£ 1.50$. This means that participants are not incentivized since their choices do not affect their rewards. This absence of incentives might be a limitation of our study because past research has shown that hypothetical questions do not always accurately predict real economic commitments (Neill, Cummings, Ganderton, Harrison, \& McGuckin, 1994). In particular, participants are more likely to overstate their preferences with hypothetical questions than with real economic commitments (List \& Gallet, 2001). In our case, participants could reveal a higher or lower tolerance to NIRs than the one they would show in reality. On the other hand, Camerer and Hogarth (1999) provide evidence that people's choices do not differ so much between incentivized and non-incentivized settings. ${ }^{18}$ According to Read (2005), there is even no basis for requiring the use of real incentives in economic experimental settings. Facing this lack of consensus, we opt for a fixed reward given the difficulty to define any incentives depending on our set of binary choices that, for some of them, imply NIRs, i.e., losses.

\footnotetext{
18 These authors review 74 experiments with no, low, or high performancebased financial incentives. They report that the modal result has no effect on mean performance, although higher payment is often associated with lower variance.
} 
Table 1

Savings behavior depending on financial literacy.

\begin{tabular}{lllll}
\hline & \multicolumn{4}{l}{ Financial literacy } \\
\cline { 2 - 5 } & 0 & 1 & 2 & 3 \\
\hline Number of participants & 9 & 25 & 49 & 103 \\
Number of regular savers & 6 & 21 & 41 & 78 \\
Regular savers (\%) & 66.66 & 84.00 & 83.67 & 75.72 \\
\hline
\end{tabular}

This table presents the number of participants and of savers by financial literacy level. Savings behavior is a binary variable: participants either save money regularly or do not. Financial literacy is an ordinal variable, with 0 and 3 as the lowest score and the highest score, respectively. The score is built on the number of correct answers provided to three questions addressing compounding, inflation, and diversification. These questions are available in Appendix A. literacy, and 3 for the highest level of financial literacy. The average level of financial literacy in our sample is relatively high at 2.33. More than half of the participants (103 out of 186) have the highest level of financial literacy (see Table 8 in Appendix B). Participants are best at compounding: $86 \%$ answer the related question correctly (see Table 7 in Appendix B). We also assess each participant's savings behavior with a binary variable (regular saver or not). The vast majority of our participants save money regularly (78\%). Table 1 shows that the proportion of regular savers is lower among participants who have the lowest level of financial literacy. This is consistent with the findings of Lusardi and Mitchell, 2011, who find that financially literate people are more likely to save money.

Table 2

Average indifference points and implicit interest rates.

\begin{tabular}{|c|c|c|c|c|c|}
\hline \multirow[b]{2}{*}{ Condition } & \multicolumn{5}{|c|}{ Time Horizon } \\
\hline & 6 months & 1 year & 2 years & 5 years & 10 years \\
\hline \multicolumn{6}{|c|}{ Panel A: Average indifference points } \\
\hline Ascending - High $(\$ 20,000)$ & $\$ 19,837.37$ & $\$ 19,622.78$ & $\$ 19,718.95$ & $\$ 19,547.62$ & $\$ 19,753.22$ \\
\hline Ascending - Low $(\$ 500)$ & $\$ 497.10$ & $\$ 499.83$ & $\$ 509.44$ & $\$ 528.21$ & $\$ 599.92$ \\
\hline Descending - High $(\$ 20,000)$ & $\$ 20,110.40$ & $\$ 20,128.33$ & $\$ 20,619.41$ & $\$ 21,234.53$ & $\$ 23,865.27$ \\
\hline Descending - Low $(\$ 500)$ & $\$ 503.43$ & $\$ 510.57$ & $\$ 524.52$ & $\$ 561.99$ & $\$ 660.62$ \\
\hline \multicolumn{6}{|l|}{ Panel B: Implicit interest rates } \\
\hline Ascending - High $(\$ 20,000)$ & $-0.80 \%$ & $-1.93 \%$ & $-1.59 \%$ & $-3.21 \%$ & $-4.30 \%$ \\
\hline Ascending - Low $(\$ 500)$ & $-0.65 \%$ & $-0.04 \%$ & $1.63 \%$ & $4.51 \%$ & $14.82 \%$ \\
\hline Descending - High $(\$ 20,000)$ & $0.73 \%$ & $0.61 \%$ & $2.93 \%$ & $5.42 \%$ & $16.27 \%$ \\
\hline Descending - Low $(\$ 500)$ & $0.76 \%$ & $2.11 \%$ & $4.61 \%$ & $10.95 \%$ & $25.97 \%$ \\
\hline
\end{tabular}

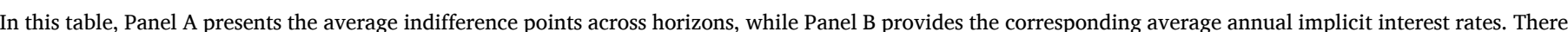

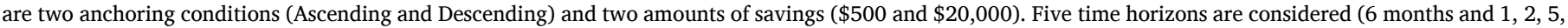
and 10 years).

\section{Results}

\subsection{Participants}

We use Prolific Academic ${ }^{19}$ to recruit participants, with prescreening based on age, nationality, and first language. Participants are required to be between 18 and 65 years old and U.S. citizens ${ }^{20}$ whose first language is English. Our average participant is 34 years old. We have more females (102) than males (84). The females in our sample are on average older than the males ( 35 versus 32 years). Most participants are full-time employed (54\%), while $20 \%$ of them are students.

The score on financial literacy for each participant is built on three questions (addressing compounding, inflation, and diversification; see Appendix A). Since the score is an equally weighted sum, its maximum is 3 , when all three questions are answered correctly, and its minimum is 0 , when none of the answers are correct. Hence, financial literacy is an ordinal variable, with four levels: 0 for the lowest level of financial literacy, 1 for a low level of financial literacy, 2 for a high level of financial

\footnotetext{
19 Prolific Academic is an online crowdsourcing platform (https://www.prolific.co/). Crowdsourcing platforms have numerous advantages. They are as reliable as lab experiments (Peer, Brandimarte, Samat, \& Acquisti, 2017). They allow for the recruitment of a large number of participants, which provides high statistical power. The speed of online experiments is also remarkable (Musch \& Reips, 2000). In addition, online experiments are cost-effective since they are often less expensive than lab experiments.

${ }^{20}$ To the best of our knowledge, NIRs on standard savings accounts have not been introduced in the US. Participants are likely to be aware that the FED policy rates and risk-free rates in general have reached all-time low levels in the aftermath of the 2008 financial crisis, but none should have been confronted with NIRs on their actual bank savings account. This makes our sample homogeneous on that aspect. Our participants are free of any biases or misinformation on NIRs.
}

\subsection{Annual implicit interest rates}

To make relevant comparisons across anchoring conditions, horizons, and amounts of savings, we need to determine annual implicit rates with a two-step process. In the first step, we determine the indifference points based on intertemporal preferences. ${ }^{21}$ In the second step, we use the indifference points to calculate the corresponding annual implicit interest rates. ${ }^{22}$

In Panel A of Table 2, we report the average indifference points depending on both the anchoring condition and the amount of savings. In the Ascending condition, for both high and low amounts and across all horizons, the average indifference points are smaller than the corresponding ones in the Descending condition. For example, in the Ascending condition, for the shortest horizon (6 months) and when the amount is high, decision-makers are indifferent between taking $\$ 20,000$ today and holding that amount in the bank to obtain $\$ 19,837.37$ in 6 months. In the Descending condition, for the same horizon and amount, participants are indifferent between $\$ 20,000$ today and $\$ 20,110.40$ in 6 months. Panel B of Table 2 presents the average annual implicit interest rates based on the indifference points reported in Panel A. The average implicit interest rates are lower in the Ascending condition than the corresponding ones in the Descending condition.

Figure 4 presents the average annual implicit interest rates. The lowest average annual implicit interest rate is observed in the Ascending condition for the high amount $(\$ 20,000)$, while the highest average annual implicit interest rate is observed in the Descending condition

\footnotetext{
21 The indifference point is calculated as the point when a participant is indifferent between consumption today or saving money for the future. Accordingly, it is an average of the upper and the lower bounds of future amounts chosen by the participants.

${ }^{22}$ We use the continuous compounding formula as in Thaler (1981)
} 

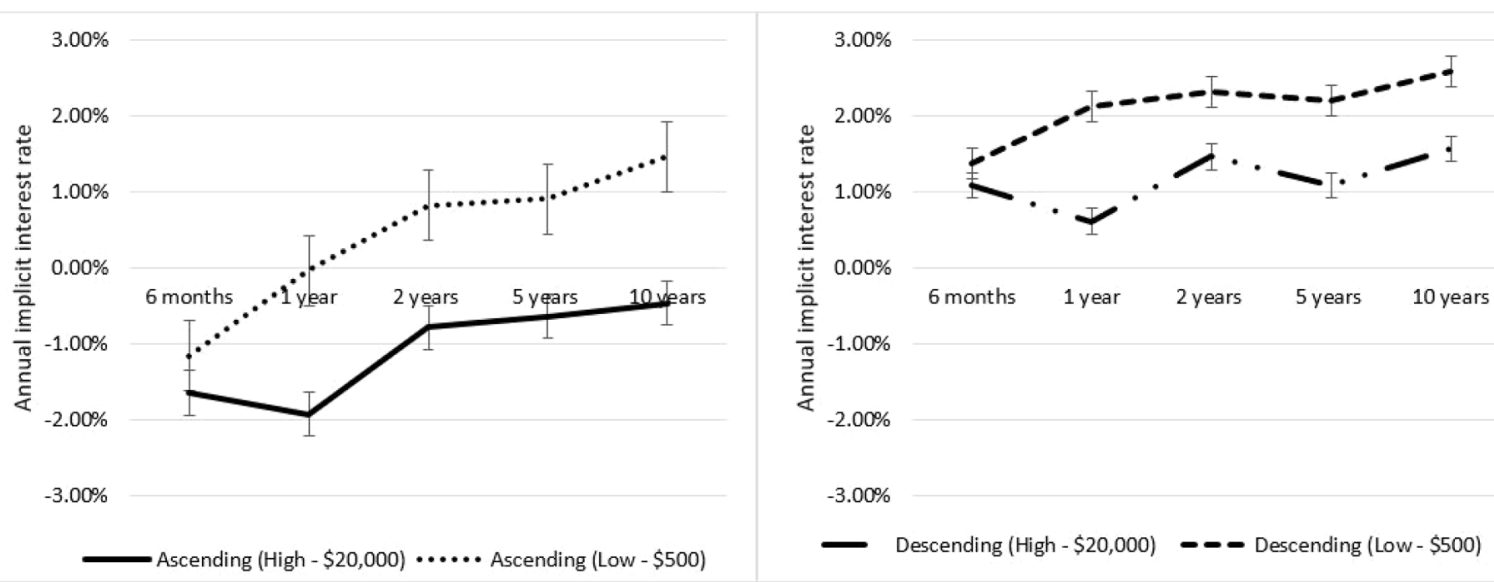

Descending (High - \$20,000) - - Descending (Low - \$500)

Fig. 4. Average annual implicit interest rates. This figure presents the average annual implicit interest rates. The horizontal axis refers to the time horizon, while the vertical axis refers to the annual implicit interest rates.

Table 3

Differences in average annual implicit interest rates - magnitude effect.

\begin{tabular}{|c|c|c|c|c|c|}
\hline \multirow[b]{2}{*}{ Condition } & \multicolumn{5}{|c|}{ Time Horizon } \\
\hline & $\begin{array}{l}6 \\
\text { months }\end{array}$ & 1 year & 2 years & 5 years & 10 years \\
\hline \multicolumn{6}{|c|}{ Panel A: Ascending condition } \\
\hline $\begin{array}{l}\text { Ascending - High } \\
\quad(\$ 20,000)\end{array}$ & $-1.65 \%$ & $\begin{array}{l}- \\
1.93 \%\end{array}$ & $\begin{array}{l}- \\
0.79 \%\end{array}$ & $\begin{array}{l}- \\
0.64 \%\end{array}$ & $\begin{array}{l}- \\
0.47 \%\end{array}$ \\
\hline $\begin{array}{l}\text { Ascending - Low } \\
\quad(\$ 500)\end{array}$ & $-1.16 \%$ & $\begin{array}{l}- \\
0.04 \%\end{array}$ & $0.82 \%$ & $0.90 \%$ & $1.46 \%$ \\
\hline $\begin{array}{l}\text { Differences (High - } \\
\text { Low) }\end{array}$ & $-0.49 \%$ & $\begin{array}{l}- \\
1.89 \%\end{array}$ & $\begin{array}{l}- \\
1.61 \%\end{array}$ & $\begin{array}{l}- \\
1.54 \%\end{array}$ & $\begin{array}{l}- \\
1.92 \%\end{array}$ \\
\hline$t$-value & -11.95 & -10.28 & -9.18 & -10.61 & -9.28 \\
\hline$p$-value & $<0.0001$ & $<0.0001$ & $<0.0001$ & $<0.0001$ & $<0.0001$ \\
\hline \multicolumn{6}{|c|}{ Panel B: Descending condition } \\
\hline $\begin{array}{l}\text { Descending - High } \\
\quad(\$ 20,000)\end{array}$ & $1.08 \%$ & $0.61 \%$ & $1.46 \%$ & $1.08 \%$ & $1.56 \%$ \\
\hline $\begin{array}{l}\text { Descending - Low } \\
\quad(\$ 500)\end{array}$ & $1.37 \%$ & $2.11 \%$ & $2.31 \%$ & $2.19 \%$ & $2.58 \%$ \\
\hline $\begin{array}{l}\text { Differences (High - } \\
\text { Low) }\end{array}$ & $-0.29 \%$ & $\begin{array}{l}- \\
1.50 \%\end{array}$ & $\begin{array}{l}- \\
0.85 \%\end{array}$ & $\begin{array}{l}- \\
1.11 \%\end{array}$ & $\begin{array}{l}- \\
1.02 \%\end{array}$ \\
\hline$t$-value & -15.07 & -15.52 & -13.69 & -10.12 & -14.22 \\
\hline$p$-value & $<0.0001$ & $<0.0001$ & $<0.0001$ & $<0.0001$ & $<0.0001$ \\
\hline
\end{tabular}

This table presents the average annual implicit interest rates for both anchoring conditions across all time horizons, the differences between the average annual interest rates related to both the high and low amounts, and the corresponding $t$-values and $p$-values conducted with paired t-test. Panel A focuses on differences in the Ascending condition, while Panel B refers to the Descending condition.

when the amount is low $(\$ 500)$.

Our first hypothesis posits a reverse magnitude effect. We conduct a paired t-test of a difference in the means of the annual implicit interest rates between the low and high amounts for each time horizon. Table 3 reports the results, with Panel A displaying those for the Ascending condition and Panel B those for the Descending condition. In both anchoring conditions, the difference between the annual implicit interest rates for the two amounts at the 6-month and 1-, 2-, 5- and 10-year horizons is negative and significant at the $1 \%$ level. These univariate findings reveal a conventional magnitude effect in both anchoring conditions: the average annual implicit interest rates are significantly lower for the high amount of savings. This evidence does not support our first hypothesis.
Table 4

Differences in average annual implicit interest rates - anchoring bias.

\begin{tabular}{|c|c|c|c|c|c|}
\hline \multirow[b]{2}{*}{ Condition } & \multicolumn{5}{|c|}{ Time Horizon } \\
\hline & $\begin{array}{l}6 \\
\text { months }\end{array}$ & 1 year & 2 years & 5 years & 10 years \\
\hline \multicolumn{6}{|c|}{ Panel A: High amount } \\
\hline $\begin{array}{l}\text { Descending - High } \\
\quad(\$ 20,000)\end{array}$ & $1.08 \%$ & $0.61 \%$ & $1.46 \%$ & $1.08 \%$ & $1.56 \%$ \\
\hline Ascending - High & - & - & - & - & - \\
\hline$(\$ 20,000)$ & $1.65 \%$ & $1.93 \%$ & $0.79 \%$ & $0.64 \%$ & $0.47 \%$ \\
\hline $\begin{array}{l}\text { Differences } \\
\text { (Descending - } \\
\text { Ascending) }\end{array}$ & $2.74 \%$ & $2.54 \%$ & $2.26 \%$ & $1.73 \%$ & $2.03 \%$ \\
\hline$t$-value & 7.25 & 7.33 & 5.91 & 5.16 & 6.26 \\
\hline$p$-value & $<0.0001$ & $<0.0001$ & $<0.0001$ & $<0.0001$ & $<0.0001$ \\
\hline \multicolumn{6}{|c|}{ Panel B: Low amount } \\
\hline $\begin{array}{l}\text { Descending - Low } \\
\quad(\$ 500)\end{array}$ & $1.37 \%$ & $2.11 \%$ & $2.31 \%$ & $2.19 \%$ & $2.58 \%$ \\
\hline $\begin{array}{l}\text { Ascending - Low } \\
\quad(\$ 500)\end{array}$ & $\begin{array}{l}- \\
1.16 \%\end{array}$ & $\begin{array}{l}- \\
0.04 \%\end{array}$ & $0.82 \%$ & $0.90 \%$ & $1.46 \%$ \\
\hline $\begin{array}{l}\text { Differences } \\
\text { (Descending - } \\
\text { Ascending) }\end{array}$ & $2.53 \%$ & $2.15 \%$ & $1.49 \%$ & $1.29 \%$ & $1.12 \%$ \\
\hline$t$-value & 5.78 & 4.89 & 3.58 & 3.45 & 3.2 \\
\hline$p$-value & $<0.0001$ & $<0.0001$ & 0.0002 & 0.0003 & 0.0008 \\
\hline
\end{tabular}

This table presents the average annual implicit interest rates for both anchoring conditions across all time horizons, the differences between the average annual implicit interest rates for the high and low amounts separately, and the corresponding $t$-values and $p$-values. Panel A focuses on the differences in the annual implicit interest rates for the high amount of savings, while Panel B refers to those for the low amount of savings.

Due to anchoring bias (and/or satisficing behavior), the average annual implicit interest rates are expected to be lower in the Ascending condition than in the Descending condition. Table 4 reports the results of a two-sample t-test assessing the differences in the average annual implicit interest rates between the two anchoring conditions. In the Ascending condition, for both the high and low amounts, the annual implicit interest rates are always significantly lower than those in the Descending condition. The largest differences are observed for the shortest horizon, i.e., $2.74 \%$ for $\$ 20,000$ and $2.53 \%$ for $\$ 500$. These univariate findings support our hypothesis. Consistent with Table 4, the proportion of decisions that tolerate NIRs is higher in the Ascending condition $(54.89 \%)$ than in the Descending condition $(20.95 \%)$. The 
Table 5

Tolerance of NIRs.

\begin{tabular}{|c|c|c|c|c|}
\hline \multirow[t]{2}{*}{ Parameter } & \multicolumn{2}{|l|}{ Model 1} & \multicolumn{2}{|l|}{ Model 2} \\
\hline & Estimate & OR & Estimate & OR \\
\hline Intercept & -0.6605 & & -0.7763 & \\
\hline Age & -0.0026 & 0.9974 & -0.0026 & 0.9974 \\
\hline Gender & -0.1656 & 0.8474 & -0.1663 & 0.8468 \\
\hline D_Year_1 & $-0.1417^{*}$ & 0.8679 & $-0.1416^{*}$ & 0.8679 \\
\hline D_Years_2 & $\begin{array}{l}- \\
0.6879 * k *\end{array}$ & 0.5027 & $\begin{array}{l}- \\
0.6898^{* * *}\end{array}$ & 0.5017 \\
\hline D_Years_5 & $\begin{array}{l}- \\
0.8295^{* k *}\end{array}$ & 0.4363 & 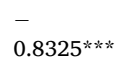 & 0.4350 \\
\hline D_Years_10 & $-\overline{1.0066^{* * *}}$ & 0.3655 & $-\overline{1.0111^{* * *}}$ & 0.3638 \\
\hline Ascending_group & $1.6093^{* * *}$ & 4.9990 & $1.8222 * * *$ & 6.1850 \\
\hline High_amount & $-\overline{0.5808 * * *}$ & 0.5594 & $\begin{array}{l}- \\
0.3169 * *\end{array}$ & 0.7280 \\
\hline $\begin{array}{l}\text { Regular_saver } \\
\text { D Low_literacy }\end{array}$ & $\begin{array}{l}0.5155^{*} \\
-0.1645\end{array}$ & $\begin{array}{l}1.6744 \\
0.8483\end{array}$ & $\begin{array}{l}0.5190^{*} \\
-0.1659\end{array}$ & $\begin{array}{l}1.6803 \\
0.8471\end{array}$ \\
\hline D_High_literacy & -0.3304 & 0.7186 & -0.3325 & 0.7171 \\
\hline D_Highest_literacy & -0.0746 & 0.9281 & -0.0756 & 0.9271 \\
\hline Ascending_group*High_amount & & & $\begin{array}{l}- \\
0.4504^{* *}\end{array}$ & 0.6370 \\
\hline $\mathrm{N}$ & 1870 & & 1870 & \\
\hline
\end{tabular}

This table reports the results of a binary logit model wherein the dependent variable is set to one when the annual implicit interest rate is negative and zero otherwise (see Equation 1). The set of explanatory variables includes both individual-varying and decision-varying variables. Gender is a binary variable set to one for men. D_Year_1, D_Year_2, D_Year_5, and D_Year_10 are binary variables set to one when the time horizon is equal to 1, 2, 5, and 10 years, respectively. Ascending_group is a binary variable set to one for participants in the Ascending condition. High_amount is a binary variable set to one when the amount is high $(\$ 20,000)$ and zero otherwise $(\$ 500)$. Regular_saver is a binary variable set to one for participants who are regular savers. D_Low_literacy, D_High_literacy, and D_Highest_literacy are binary variables set to one when financial literacy scores are at the low, high, and highest levels, respectively. $* * *, * *$, and $*$ indicate significance at $1 \%, 5 \%$, and $10 \%$, respectively. $N$ gives the number of observations. OR refers to odds ratios. Standard errors are clustered by participant.

details regarding acceptance of NIR, i.e., the number of decisions in which participants opt to hold their savings in the presence of NIRs, are provided in Table 9 in Appendix C.

\subsection{Tolerance of NIRs}

To assess tolerance of NIRs, we estimate a binary logit model wherein the dependent variable, $T T N I R_{i, d}$, is set to one when the annual implicit interest rate associated with a given decision $d$ made by participant $i$ is negative and zero otherwise. Our set of explanatory variables includes both individual-varying and decision-varying variables. The individualvarying variables are age, gender, savings behavior, financial literacy, and the anchoring condition. Gender is defined as a binary variable $\left(\right.$ Gender $_{i}$ ) that is set to one for men. Savings behavior is captured by a binary variable (Regular_saver ${ }_{i}$ ) that equals one for participants who are regular savers. Financial literacy is also coded using three binary variables (D_Low_literacy $i, D \_H i g h \_l i t e r a c y$, , and $D \_$Highest_literacy $\left.i\right)$, which are set to one when financial literacy scores are at the low, high, and highest levels. ${ }^{23}$ To control for the anchoring condition, we use an additional binary variable (Ascending_group ${ }_{i}$ ) set to one for participants

\footnotetext{
${ }^{23}$ We also estimate a logit model wherein we replace the binary variables for financial literacy with a dummy for compounding, which is set to one when participants provided a correct answer to the specific question about compounding and zero otherwise. We do not find any significant result for compounding and obtain similar findings overall (available upon request).
}

in the Ascending condition. The time horizon and amount of savings are the two decision-varying variables. The time horizon is included by using four binary variables $\left(D_{-} Y e a r_{-} 1_{i, d}, D_{-} Y e a r_{-} 2_{i, d}, D_{-} Y e a r_{-} 5_{i, d}\right.$, and $\left.D_{-} Y_{e a r}{ }_{-} 10_{i, d}\right)$ set to one for time horizons of $1,2,5$, and 10 years. The amount of savings is also coded as a binary variable (High_amount $t_{i, d}$ ) that is set to one when the amount is high $(\$ 20,000)$ and zero otherwise (\$500).

All these explanatory variables are not highly correlated (see Table 10 in Appendix D). Since we deal with panel data (with ten decisions per participant across 186 participants), we cluster standard errors by participant (Petersen, 2009) when estimating the resulting model:

$$
\begin{aligned}
& \text { TTNIR }_{i, d}=\beta_{0}+\beta_{1} \text { Age } e_{i}+\beta_{2} \text { Gender }_{i}+\beta_{3} \text { D.Year } 1_{i, d}+\beta_{4} \text { D. Years. } 2_{i, d}
\end{aligned}
$$

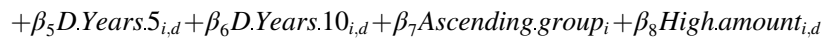

$$
\begin{aligned}
& +\beta_{9} \text { Regular saver }_{i}+\beta_{10} \text { DLow.literacy }_{i}+\beta_{11} \text { D.High.literacy }_{i} \\
& +\beta_{12} \text { DHighest.literacy }_{i}+\epsilon_{i, d}
\end{aligned}
$$

Table 5 presents the results for two versions of the logit model above. Our baseline model (Model 1) includes the aforementioned independent variables. When we focus on decision-varying variables, tolerance of NIRs is negatively related to both the amount of savings and the time horizon at the $1 \%$ level (except for the 1-year horizon). Tolerance of NIRs is less likely when the amount of savings is high than when the amount of savings is low. All else being equal, the odds of a decision to accept an NIR decreases by approximately $44 \%$ when the amount of savings is high. In other words, the higher the amount at stake, the lower is the tolerance of NIRs. This finding is consistent with the reverse magnitude effect posited in our first hypothesis. One possible reason for this effect is that the interest to be paid appears lower in absolute terms for the small amount of savings than for the corresponding interest on the large amount of savings.

For the four time horizons (1, 2, 5, and 10 years), the likelihood of tolerating NIRs is lower than for the 6-month horizon. The odds of a decision to accept an NIR decrease when the time horizon increases. More precisely, compared to the 6-month horizon, when the time horizon is 1 year, the odds of a decision to accept an NIR on savings are multiplied by a factor of 0.9974 (i.e., decrease by $0.26 \%$ ). For a 10 -year horizon, the odds of a decision to tolerate an NIR on savings are multiplied by a factor of 0.3655 (i.e., decrease by $63.45 \%$ ). Shorter horizons are then associated with a higher tolerance of NIRs than that at longer horizons. This result supports our second hypothesis, i.e., people are reluctant to accept recurrent losses or to commit to losses for longer time horizons.

Looking at individual-varying variables, the results for both the anchoring condition and savings behavior are statistically significant. In regards to the anchoring condition, our hypothesis is confirmed. Participants in the Ascending condition are much more likely to tolerate NIRs than participants in the Descending condition. The odds of accepting NIRs on savings are higher by a factor of 4.9990 in the Ascending condition than those in the Descending condition. This strong result is consistent with the anchoring effect. Alternatively, it might also be consistent with satisficing behavior, i.e., participants are more likely to tolerate NIRs in the Ascending condition because NIRs are presented first. As for regular savers, they are more likely to tolerate NIRs than nonregular savers, which confirms our third hypothesis. The odds of a participant tolerating NIRs on savings increase by $67.44 \%$ when he/she is a regular saver. This higher tolerance to NIRs can be related to the status quo bias, a higher familiarity with savings deposits, and/or a future-oriented mindset (i.e., regular savers have put savings aside for the future and NIRs cannot compromise that future).

We find no significant results for financial literacy and thus no support for our fourth hypothesis. Since the level of financial literacy is pretty high among our participants, we cannot exclude that this finding 
Table 6

OLS regressions - annual implicit interest rates.

\begin{tabular}{lll}
\hline Parameter & Ascending condition & Descending condition \\
\hline Intercept & -0.0082 & 0.0005 \\
Age & 0.0001 & 0.0000 \\
Gender & 0.0022 & 0.0016 \\
D_Year_1 & $0.0042^{* * *}$ & 0.0014 \\
D_Years_2 & $0.0142^{* * *}$ & $0.0066^{* * *}$ \\
D_Years_5 & $0.0154^{* * *}$ & $0.0041^{* *}$ \\
D_Year_10 & $0.0190^{* * *}$ & $0.0086^{* * *}$ \\
High_amount & $0.0149^{* * *}$ & $0.0094^{* * *}$ \\
Regular_saver & -0.0074 & $-0.0095^{* *}$ \\
D_Low_literacy & -0.0108 & 0.0176 \\
D_High_literacy & -0.0126 & 0.0153 \\
D_Highest_literacy & -0.0107 & 0.0108 \\
N & 920 & 950 \\
\hline
\end{tabular}

This table reports the results for two OLS regression models wherein the dependent variable is the annual implicit interest rate. The latter is a discrete numerical variable that can take $-4,-3,-1,1,3$, or $4 \%$. The set of explanatory variables includes both individual-varying and decision-varying variables. Gender is a binary variable set to one for men. D_Year_1, D_Year_2, $D_{-} Y e a r_{-} 5$, and $D_{-} Y e a r_{-} 10$ are binary variables set to one when the time horizon is equal to 1, 2, 5, and 10 years, respectively. High_amount a binary variable set to one when the amount is high $(\$ 20,000)$ and zero otherwise $(\$ 500)$. Regular_saver is a binary variable set to one for participants who are regular savers. D_Low_literacy, D_High_literacy, and D_Highest_literacy are binary variables set to one when financial literacy is at the low, high, and highest levels, respectively. ${ }^{* * *}, * *$, and $*$ indicate significance at $1 \%, 5 \%$, and $10 \%$, respectively. $\mathrm{N}$ gives the number of observations. Standard errors are clustered by participant.

is (at least partially) due to a lack of heterogeneity in the sample. Age and gender are the usual control variables. We know from the literature that younger people are more likely to save than middle-aged individuals (Heckman and Hanna, 2015) and that the latter save little compared to older generations, who oversave (Furnham and Argyle, 1998). Regarding gender, previous evidence suggests that women save less than men (Ohlund, 2017). However, we find no significant relationship between either age or gender and tolerance of NIRs on savings.

Our hypothesis about the reverse magnitude effect yields expectations whose strength could depend on the anchoring condition. Hence, we add an interaction variable between the amount of savings and the anchoring condition in our baseline model. The results are provided in Model 2 of Table 5. The interaction variable exhibits a negative coefficient at the $5 \%$ level of significance. The relationship between the amount of savings and tolerance of NIRs depends on the anchoring condition. When the amount is high, the likelihood of accepting NIRs is lower in the Ascending condition than in the Descending condition. This is consistent with a stronger reverse magnitude effect in the Ascending condition. The odds of tolerating NIRs decrease by $36.30 \%$ for the high amount of savings if a participant is in the Ascending condition.

\subsection{Heterogeneity in annual implicit interest rates}

As a side analysis, we investigate heterogeneity in the annual implicit interest rates with an OLS regression for the Ascending and Descending conditions separately. For this purpose, we estimate two models wherein the dependent variable is the annual implicit interest rate associated with a given decision ${ }^{24}$ and the set of independent variables is the same as in our baseline logit model (see Model 1 in Table 5), except for the anchoring condition. Table 6 provides the results with standard errors clustered by participant. When the amount of savings is high, the annual implicit interest rate increases by $1.49 \%$ in the Ascending condition and

\footnotetext{
24 The annual implicit interest rate is a discrete variable that can be $-4,-3$, $-1,1,3$, or $4 \%$ (coded as $-0.04,-0.03,-0.01,0.01,0.03$, and 0.04 ).
}

by $0.94 \%$ in the Descending condition. Regardless of the anchoring condition, the higher the amount, the higher is the annual implicit interest rate. This finding supports our first hypothesis. In addition, the marginal effect appears stronger in the Ascending condition, as expected. As the time horizon increases, the annual implicit interest rate increases. For the 1-year horizon in the Ascending condition, the annual implicit interest rate increases by $0.42 \%$ compared to the rate for the 6month horizon. The increase is approximately $1.42 \%$ for the 2 -year horizon, $1.54 \%$ for the 5 -year horizon, and $1.90 \%$ for the 10 -year horizon. The annual implicit rates also increase with the time horizon in the Descending condition, but the corresponding coefficient estimates are weaker. These results support our second hypothesis. When participants are regular savers, the annual implicit interest rates decrease. However, only the decrease of $0.95 \%$ in the Descending condition is statistically significant. These findings partially support our third hypothesis. For financial literacy, the results are again not statistically significant. In line with our previous findings, we again find no significant results for age and gender.

\section{Conclusion}

In this paper, we use an experimental setting that enables us to address intertemporal preferences in savings decisions and reveal what leads people to tolerate NIRs. Specifically, our experiment is a mixed design with one between-subject factor, the anchoring condition (Ascending, moving from NIRs to PIRs vs. Descending, moving from PIRs to NIRs), and two within-subject factors: time horizon (6 months and $1,2,5$, and 10 years) and the amount of savings ( $\$ 500$ vs. $\$ 20,000)$.

We provide evidence that tolerance of NIRs is negatively related to both the time horizon and the amount of savings. The higher the amount, the lower is the tolerance of NIRs. This is consistent with a reverse magnitude effect, meaning that the interest to be paid appears lower in absolute terms for the small amount of savings than that for the large amount of savings. As the time horizon increases, tolerance of NIRs decreases. Shorter horizons are thus associated with a higher tolerance of NIRs. This suggests that it is harder for people to commit to losses for a long time horizon (and incur recurrent losses in our case).

We extend the previous literature by relating tolerance of NIRs to actual savings behavior, financial literacy, and anchoring bias. Regular savers are more likely to tolerate NIRs than nonregular savers. We relate this result to the status quo bias, a higher familiarity with savings deposits, and/or a future-oriented mindset (i.e., regular savers care about the future and NIRs will not prevent them from putting savings aside for that future). As for the anchoring effect, we find a higher tolerance of NIRs on savings when participants are anchored towards NIRs on savings (i.e., in the Ascending condition). We find however no significant results for financial literacy. Since the level of financial literacy is particularly high among our participants, we cannot rule out that this finding is (at least partially) due to a lack of heterogeneity in the sample.

We should point out that what we observe in our experiment seems consistent with the actual savings behavior of people in countries that are experiencing all-time low rates or NIRs. Our findings indeed confirm that people may be willing to continue to save money (instead of spending it) even if this means they will certainly lose some money. This is an important finding for policymakers and banks considering the implementation of NIRs on bank deposits. Our results provide relevant insights about some important factors (amount of money at stake, time horizon), conditions (facing NIRs or PIRs first), or individual characteristics (savings behavior, financial literacy) that can affect this propensity. When interest rates are very low or already negative, tolerance of NIRs is more likely to increase. Large and small depositors should be treated differently, since small depositors appear more likely to tolerate NIRs on savings. Different treatments could also be applied to regular and nonregular savers, since the latter are less likely to tolerate NIRs.

Our experimental findings, as ecologically valid as they may be, cannot entirely reflect the dynamics and complexity of individual 
savings behaviors in reality. First, the absence of incentives for participants might be a limitation of our study. Since their choices do not affect their rewards, participants might have overstated their preferences in our hypothetical questions, i.e., have revealed a higher or lower tolerance to NIRs than the one they would have shown with real economic commitments. Second, another shortcoming might be that participants make binary choices in our setting, i.e., either continue to save money or spend it immediately (on goods and/or services). This setting forces participants to make "all or none" decisions that are infrequent in reallife. Although the binary choice-based method has been shown to lead to better predictions of real-world outcomes (Hardisty, Thompson, Krantz, \& Weber, 2013b), we acknowledge that the tolerance for NIR might differ when people have the possibility to either save or invest part of their money. In the same vein, we do not propose other alternatives to participants, such as investing in the stock market or paying off existing debts. Providing participants with a larger set of alternatives would give them more freedom in designing their own choices. Third, we find that the tolerance for NIRs is related to the saved amount. Since the amount of money at stake is also the participant's wealth (which is experimentally manipulated), it is hard to distinguish between the effect of the amount saved and the wealth effect. Finally, our study relies on binary choices between present and future amounts, revealing direct dollar gains/losses to participants. Presenting interest rates (with or instead of future amounts in dollars) to participants might provide insights into how much people's reactions differ when facing dollar amounts and/or interest rates. All these points of attention highlight potential moderators of the current effects that may be examined in future research.

\section{Appendix A. Financial literacy - questions}

QUESTION 1: Suppose you have $\$ 100$ in a savings account and the interest rate is $2 \%$ per year. After 5 years, how much do you think you would have in the account if you leave the money to grow?

- More than $\$ 102$

- Exactly $\$ 102$

- Less than $\$ 102$

- Do not know

- Refuse to answer

QUESTION 2: Imagine that the interest rate on your savings account is $1 \%$ per year and inflation is $2 \%$ per year. After 1 year, how much would you be able to buy with the money in this account?

- More than today

- Exactly the same

- Less than today

- Do not know

- Refuse to answer

QUESTION 3: Please tell me whether this statement is true or false. "Buying a single company's stock usually provides a safer return than a stock mutual fund".

- True

- False

- Do not know

- Refuse to answer

Appendix B. Financial literacy - statistics
Table 7

Financial literacy by component.

\begin{tabular}{lll}
\hline Question & Percentage & $\mathrm{N}$ \\
\hline Compounding & $86 \%$ & 160 \\
Inflation & $76 \%$ & 141 \\
Diversification & $70 \%$ & 130 \\
\hline
\end{tabular}

This table provides the percentage of participants who correctly answered each question addressing financial literacy. $\mathrm{N}$ gives the number of participants.

Table 8

Financial literacy score.

\begin{tabular}{ll}
\hline Financial literacy score & Percentage \\
\hline 0 & $4.81 \%$ \\
1 & $13.37 \%$ \\
2 & $26.20 \%$ \\
3 & 55.61 \\
\hline
\end{tabular}

This table provides the percentage of participants who received each financial literacy score. Computed using the questions presented in Appendix A, the score is an ordinal variable with four levels: 0 for the lowest level of financial literacy, 1 for a low level of financial literacy, 2 for a high level of financial literacy, and 3 for the highest level of financial literacy.

\section{Appendix C. Acceptance of NIRs}

\section{Table 9}

Table 9

Acceptance of NIRs.

\begin{tabular}{lll}
\hline Description & $\begin{array}{l}\text { Ascending } \\
\text { condition }\end{array}$ & $\begin{array}{l}\text { Descending } \\
\text { condition }\end{array}$ \\
\hline $\begin{array}{c}\text { Percentage of decisions indicating } \\
\text { acceptance of NIRs }\end{array}$ & $54.89 \%$ & $20.95 \%$ \\
$\begin{array}{c}\text { Number of decisions indicating } \\
\text { acceptance of NIRs }\end{array}$ & 505 & 199 \\
Total number of decisions & 920 & 950 \\
\hline
\end{tabular}

This table reports the proportion of decisions indicating acceptance of NIRs in both the Ascending and Descending conditions. 
Table 10

Spearman correlations.

Spearman correlation coefficients

\begin{tabular}{|c|c|c|c|c|c|c|}
\hline & Savings amount & Anchoring condition & Horizon & Savings behavior & Financial literacy & Annual implicit interest rate \\
\hline Savings amount & 1 & 0 & 0 & 0 & 0 & $0.24862^{* * *}$ \\
\hline Anchoring condition & 0 & 1 & 0 & $-0.04728^{* *}$ & 0.02657 & $-0.33066^{* * *}$ \\
\hline Horizon & 0 & 0 & 1 & 0 & 0 & $0.14993^{* * *}$ \\
\hline Savings behavior & 0 & $-0.04728 * *$ & 0 & 1 & $-0.06501^{* * *}$ & $-0.11109^{* * *}$ \\
\hline Financial literacy & 0 & 0.02657 & 0 & $-0.06501^{* * *}$ & 1 & $-0.06434 * * *$ \\
\hline Annual implicit interest rate & $0.24862^{* * *}$ & $-0.33066^{* * *}$ & $0.14993^{* * *}$ & $-0.11109^{* * *}$ & $-0.06434^{* * *}$ & 1 \\
\hline
\end{tabular}

This table provides the Spearman correlation coefficients for six variables: savings amount, anchoring condition, time horizon, savings behavior, financial literacy, and annual implicit interest rate. The savings amount is a binary variable set to one when the amount of savings is high $(\$ 20,000)$. The time horizon can be 6 months (expressed in years, i.e., 0.5), 1 year, 2 years, 5 years, or 10 years. The anchoring condition is a binary variable set to one for the Ascending condition (and zero for the Descending condition). Savings behavior is a binary variable set to one for regular savers. Financial literacy is an ordinal variable with four levels: 0 for the lowest level of financial literacy, 1 for a low level of financial literacy, 2 for a high level of financial literacy, and 3 for the highest level of financial literacy. The annual implicit interest rate is a discrete numerical variable that can take $-4,-3,-1,1,3$, or $4 \%$. ***, $* *$, and * indicate significance at $1 \%, 5 \%$, and $10 \%$, respectively.

\section{References}

Agarwal, R., \& Kimball, M. (2015). Breaking through the zero lower bound. Technical report, IMF Working Paper WP/15/224. Washington: International Monetary Fund, October.

Ainslie, G., \& Haslam, N. (1992). Hyperbolic discounting. In G. Loewenstein, \& J. Elster (Eds.), Choice over time (pp. 57-92). New York, NY, US: Russell Sage Foundation.

Aizenman, J., Cavallo, E., \& Noy, I. (2015). Precautionary strategies and household saving. Open Economies Review, 26(5), 911-939.

Altavilla, C., Burlon, L., Giannetti, M., \& Holton, S. (2019). Is there a zero lower bound? The effects of negative policy rates on banks and firms. ECB Working Paper.

Anantanasuwong, K. (2019). How financial literacy impacts retirement savings: The role of present bias and exponential growth bias. Available at SSRN: https://ssrn. com/abstract $=336478110.2139 /$ ssrn. 3364781 .

Ariely, D., \& Norton, M. I. (2008). How actions create - not just reveal - preferences. Trends in Cognitive Sciences, 12(1), 13-16. https://doi.org/10.1016/j. tics.2007.10.008.http://www.sciencedirect.com/science/article/pii/S1364661 307003014

Block, W. E. (1978). The negative interest rate: Toward a taxonomic critique. Journal of Libertarian Studies, 2(2), 121-124.

Baars, M., Cordes, H., \& Mohrschladt, H. (2020). How negative interest rates affect the risk-taking of individual investors: Experimental evidence. Finance Research Letters, 32.

Bracha, A. (2020). Investment decisions and negative interest rates. Management Science, 66(11), 5316-5340.

Breuer, W., Soypak, C. K., \& Steininger, B. I. (2020). Conventional or reverse magnitude effect for negative outcomes: A matter of framing. Available at SSRN: https://ssrn. com/abstract $=217678410.2139 / \mathrm{ssrn} .2176784$.

Brown, B. (2018). Negative interest rates and the war against cash. The case against 2 per cent inflation (pp. 149-163). Springer.

Camerer, C. F., \& Hogarth, R. M. (1999). The effects of financial incentives in experiments: A review and capital-labor-production framework. Journal of Risk and Uncertainty, 19, 7-42.

Chao, L.-W., Szrek, H., Pereira, N. S., \& Pauly, M. V. (2009). Time preference and its relationship with age, health, and survival probability. Judgment and Decision Making, 4(1), 1-19.

Chen, D. L., Schonger, M., \& Wickens, C. (2016). oTree-an open-source platform for laboratory, online, and field experiments. Journal of Behavioral and Experimental Finance, 9, 88-97.

Cialdini, R. B. (2009). Influence: the psychology of persuasion. Harper Collins.

David-Pur, L., Galil, K., \& Rosenboim, M. (2020). To decrease or not to decrease: The impact of zero and negative interest rates on investment decisions. Journal of Behavioral and Experimental Economics, 87, 101571.

Efendic, E., D'Hondt, C., De Winne, R., \& Corneille, O. (2019). Negative interest rates may be more psychologically acceptable than assumed: Implications for savings. Available at SSRN: https://ssrn.com/abstract $=3494988$.

Europe (2019). European commission, directorate-general for economic and financial affairs. European Economic Forecast: Spring 2019,.

Fisher, I. (1930). The theory of interest, as determined by impatience to spend income and opportunity to invest it. Augustusm Kelly Publishers, Clifton.

Furnham, A., \& Argyle, M. (1998). The psychology of money. Taylor \& Frances/Routledge.

Ganzach, Y., \& Wohl, A. (2018). A behavioral theory of the effect of the risk-free rate on the demand for risky assets. Journal of Behavioral and Experimental Economics, 76, 23-27. https://doi.org/10.1016/j.socec.2018.06.006.http://www.sciencedirect.co $\mathrm{m} / \mathrm{science/article/pii/S2214804318302994}$

Hardisty, D. J., Appelt, K. C., \& Weber, E. U. (2013a). Good or bad, we want it now: Fixed-cost present bias for gains and losses explains magnitude asymmetries in intertemporal choice. Journal of Behavioral Decision Making, 26(4), 348-361. https:// doi.org/10.1002/bdm.1771.https://onlinelibrary.wiley.com/doi/abs/10.1002/b dm. 1771

Hardisty, D. J., Thompson, K. F., Krantz, D. H., \& Weber, E. U. (2013b). How to measure time preferences: An experimental comparison of three methods. Judgment \& Decision Making, 8(3), 236-249.
He, P., Huang, L., \& Wright, R. (2008). Money, banking, and monetary policy. Journal of Monetary Economics, 55(6), 1013-1024. https://doi.org/10.1016/j.

jmoneco.2008.06.004.http://www.sciencedirect.com/science/article/pii/S0304393 208000858

Heckman, S. J., \& Hanna, S. D. (2015). Individual and institutional factors related to lowincome household saving behavior. Journal of Financial Counseling and Planning, 26 (2), 187-199.

Hong, G. H., \& Kandrac, J. (2018). Pushed past the limit? How Japanese banks reacted to negative interest rates. IMF Working Paper 18/131.

Itzkowitz, J., Itzkowitz, J., \& Rothbort, S. (2015). ABCs of trading: Behavioral biases affect stock turnover and value*. Review of Finance, 20(2), 663-692.

Kahneman, D., \& Tversky, A. (1979). Prospect theory: An analysis of decision under risk. Econometrica, 47(2), 263-291.http://www.jstor.org/stable/1914185

Kimball, M. S. (2015). Negative interest rate policy as conventional monetary policy. National Institute Economic Review, 234(1), R5-R14.

Lahav, E., Benzion, U., \& Shavit, T. (2011). The effect of military service on soldiers' time preferences-evidence from Israel. Judgment and Decision Making, 6(2), 130.

Lahav, E., Rosenboim, M., Shavit, T., et al. (2015). Financial literacy's effect on elicited subjective discount rate. Economics Bulletin, 35(2), 1360-1368.

Lian, C., Ma, Y., \& Wang, C. (2018). Low interest rates and risk-taking: Evidence from individual investment decisions. The Review of Financial Studies, 32(6), 2107-2148.

Lilley, A., \& Rogoff, K. (2020). The case for implementing effective negative interest rate policy. Strategies for Monetary Policy. Stanford: Hoover Institution Press.

List, J. A., \& Gallet, C. A. (2001). What experimental protocol influence disparities between actual and hypothetical stated values? Environmental and Resource Economics, 20(3), 241-254.

Lord, R. A. (1985). The legal history of safekeeping and safe deposit activities in the United States. Ark. L. Rev., 38, 727.

Lugilde, A., Bande, R., \& Riveiro, D. (2019). Precautionary saving: A review of the empirical literature. Journal of Economic Surveys, 33(2), 481-515.

Lusardi, A. (2008). Household saving behavior: The role of financial literacy, information, and financial education programs. Technical Report. National Bureau of Economic Research.

Lusardi, A., \& Mitchell, O. S. (2007). Baby boomer retirement security: The roles of planning, financial literacy, and housing wealth. Journal of Monetary Economics, 54 (1), 205-224.

Lusardi, A., \& Mitchell, O. S. (2011). Financial literacy around the world: an overview. Journal of Pension Economics \& Finance, 10(4), 497-508. https://doi.org/10.1017/ S1474747211000448.

Maggio, M. D., \& Kacperczyk, M. (2017). The unintended consequences of the zero lower bound policy. Journal of Financial Economics, 123(1), 59-80. https://doi.org/ 10.1016/j.jfineco.2016.09.006.http://www.sciencedirect.com/science/article/pii/ S0304405X1630157X

Meier, S., \& Sprenger, C. D. (2013). Discounting financial literacy: Time preferences and participation in financial education programs. Journal of Economic Behavior \& Organization, 95, 159-174.

Merrigan, P., \& Normandin, M. (1996). Precautionary saving motives: An assessment from UK time series of cross- sections. The Economic Journal, 106(438), 1193-1208.

Musch, J., \& Reips, U.-D. (2000). A brief history of web experimenting. Psychological experiments on the internet (pp. 61-87). Academic Press.

Neill, H. R., Cummings, R. G., Ganderton, P. T., Harrison, G. W., \& McGuckin, T. (1994). Hypothetical surveys and real economic commitments. Land Economics, 70(2), 145-154.

Ohlund, S. (2017). Why can't a woman invest more like a man? Gender differences in investment behaviour. Gender Differences in Investment Behaviour.

Peer, E., Brandimarte, L., Samat, S., \& Acquisti, A. (2017). Beyond the turk: Alternative platforms for crowdsourcing behavioral research. Journal of Experimental Social Psychology, 70, 153-163.

Petersen, M. A. (2009). Estimating standard errors in finance panel data sets: Comparing approaches. The Review of Financial Studies, 22(1), 435-480.

Read, D. (2005). Monetary incentives, what are they good for? Journal of Economic Methodology, 12(2), 265-276. 
Read, D., Frederick, S., \& Scholten, M. (2013). DRIFT: An analysis of outcome framing in intertemporal choice. Journal of Experimental Psychology: Learning, Memory, and Cognition, 39(2), 573-588. https://doi.org/10.1037/a0029177.

Robles, E., \& Vargas, P. A. (2007). Functional parameters of delay discounting assessment tasks: Order of presentation. Behavioural Processes, 75(2), 237-241. https://doi.org/10.1016/j.beproc.2007.02.014.

Samuelson, W., \& Zeckhauser, R. (1988). Status quo bias in decision making. Journal of Risk and Uncertainty, 1(1), 7-59.

Stix, H. (2013). Why do people save in cash? Distrust, memories of banking crises, weak institutions and dollarization. Journal of Banking \& Finance, 37(11), 4087-4106.

Thaler, R. (1980). Toward a positive theory of consumer choice. Journal of Economic Behavior \& Organization, 1(1), 39-60.
Thaler, R. (1981). Some empirical evidence on dynamic inconsistency. Economics Letters, 8(3), 201-207.

Tversky, A., \& Kahneman, D. (1974). Judgment under uncertainty: Heuristics and biases. Science, 185(4157), 1124-1131. https://doi.org/10.1126/science.185.4157.1124.

Urminsky, O., \& Zauberman, G. (2015). The psychology of intertemporal preferences. The Wiley Blackwell Handbook of Judgment and Decision Making, 2, 141-181.

Van Rooij, M. C. J., Lusardi, A., \& Alessie, R. J. M. (2012). Financial literacy, retirement planning, and household wealth. The Economic Journal, 122(560), 449-478.

Zauberman, G., \& Lynch, J. G., Jr. (2005). Resource slack and propensity to discount delayed investments of time versus money. Journal of Experimental Psychology: General, 134(1), 23-27. 